\section{New Theory}

ISSN: 2149-1402
36 (2021) 117-126

Journal of New Theory

https://dergipark.org.tr/en/pub/jnt

Open Access

\title{
A Robust Alternative to Environmental Performance Index
}

\author{
Hasan Bulut ${ }^{1}$ (1)
}

\begin{abstract}
A composite index called the Environmental Performance Index (EPI) was obtained to
Article History

Received: 01 Sep 2021

Accepted: 22 Sep 2021

Published: 30 Sep 2021

10.53570/jnt.989890

Research Article

evaluate countries' environmental performance. This index was calculated for 180 countries concerning 24 environmental indicators. However, it is well known that there are huge differences between countries regarding environmental factors besides social, economic, and cultural factors. This case aggravates the doubt that the data set has outliers. Therefore, the index values should be obtained such that they are unsensitive to outliers. This study aims to generate a composite index, which is a robust alternative to EPI. For this aim, we use the Robust Principal Component Analysis (ROBPCA) and the Technique for Order Preferences by Similarity to an Ideal Solution (TOPSIS), which is a multicriteria decision-making method.
\end{abstract}

Keywords - Environmental performance index (EPI), robust EPI, ROBPCA, TOPSIS, composite index

Mathematics Subject Classification (2020) - 62P12, 62H25

\section{Introduction}

Rapid industrialization and population growth cause harmful effects on the environment. In recent years, even ordinary people have realized this fact because of global warming and climate change. Therefore, we need evaluation and comparing countries concerning environmental factors. For this aim, a composite index called EPI was defined to measure the environmental performance of countries. This index was obtained with the collaboration of the Yale Center for Environmental Law and Policy (YCELP), Yale University, Columbia University Center for International Earth Science Information Network (CIESIN), and the World Economic Forum (WEF). The result of this index was released in Davos, Switzerland, at the annual meeting of the World Economic Forum in 2018. According to this report, 180 countries were sorted according to their EPI values, calculated from 24 environmental indicators [1].

In the literature, there are many studies related to environmental factors. In some of these studies, researchers investigated the relationship between the environmental performance of counties and different factors, such as socioeconomic, cultural, financial, ideological, economic growth [2-7]. In other studies, authors focused on obtaining a new composite index, which measures the environmental performance of countries, by using data envelopment analysis and Malmquist approaches [8-13].

Also, the principal components analysis (PCA) is one of the valuable methods to obtain a composite index [14]. Generally, researchers are interested in topics on human development, quality of life, and economic development in the studies that purpose a composite index using PCA [15-19]. Moreover, Bulut and Öner used robust PCA to obtain a composite index that is not sensitive to outliers. Thus, they evaluated the regions

${ }^{1}$ hasan.bulut@omu.edu.tr (Corresponding Author)

Department of Statistics, Faculty of Science and Letter, Ondokuz Mayıs University, Samsun, Turkey 
robustly in Turkey about their socioeconomic development [20]. Also, Alpaykut investigated the well-being of cities in Turkey by using classical PCA, which is sensitive to outliers, and TOPSIS methods [21].

It is well known that the economic and cultural features of countries may affect environmental factors. For example, companies may call in their top model cars because of unsuitable emissions in a developed country, while old vehicles may be on the roads by polluting the environment in an undeveloped country. Because of similar reasons, when countries' environmental performance is evaluated, it should not forget that the data sets consist of countries having different development levels. This case may cause the data set to include outliers. Hence, a robust approach is needed to obtain a composite index from like data.

This study purposes construction of a composite index, which is not sensitive to outliers, to evaluate countries' environmental performance. For this purpose, we use the ROBPCA method, which is a robust principal component analysis algorithm, and the TOPSIS algorithm, which is a multi-criteria decision method. In this way, we have robustly constructed a composite index measuring the environmental performances of countries and sort countries according to these values.

The remainder of the paper is organized as follows. The principal component analysis and TOPSIS methods are introduced in Section 2. In Section 3, a robust alternative to the EPI is constructed called the robust EPI (REPI). The REPI values of countries are obtained, and the countries are ordered according to these values. Finally, we conclude from the obtained results in the last section.

\section{Materials and methods}

In this section, we introduce the principal component analysis and TOPSIS methods used to construct a composite index called robust environmental performance index.

\subsection{Principal Component Analysis}

The principal component analysis is one of the most popular multivariate statistical methods. The PCA aims to obtain the new variables, which are the linear combinations of variables that are correlated with each other, and components number is less than the number of the original variables $(p)$. These new variables are called principal components. However, it is well known that classical PCA is sensitive to outliers [20]. A robust principal component analysis method called ROBPCA was developed [22].

The ROBPCA algorithm consists of three stages which are given below.

- Stage 1: The data is reduced to space that has maximum $(n-1)$ dimension using the projection pursuit approach.

- Stage 2: The initial covariance matrix $\Sigma_{0}$ is obtained, and $q$, which is the number of important components, is determined.

- Stage 3: The data points are projected on this subspace where their location and scatter matrix are robustly estimated, from which its $k$ nonzero eigenvalues $\lambda_{1}, \lambda_{2}, \ldots, \lambda_{q}$ are computed. The corresponding eigenvectors are the $q$ robust principal components $[20,22]$

Principal component scores are obtained from (1):

$$
T_{n, q}=\left(X_{n, p}-1_{n} \widehat{\mu}^{T}\right) P_{p, q}
$$

where $X: n \times p$ is data matrix, $n$ is observation number, $p$ is the variable number, $P: p \times q$ is eigenvectors matrix, $\widehat{\mu}$ which is called a robust location estimation is a column vector with $p$-dimension $1_{n}$ is the column vector with all $n$ components equal to 1 , and $(.)^{T}$ is the transpose operator. The robust scatter matrix is also calculated using spectral demonstration, as below

$$
\Sigma_{p, p}=P_{p, q} L_{q, q} P_{q, p}^{\prime}
$$

where $L_{q, q}$ is eigenvalues matrix [22]. 
An essential advantage of the ROBPCA algorithm is that it detects outliers by calculating orthogonal and score distances and using critical values for these distances. The critical value of score distance is $\sqrt{\chi_{q, 0.975}^{2}}$ and the critical value of the orthogonal distance is $\left(\hat{\mu}+\hat{\sigma} Z_{0.975}\right)^{2}$, where $g_{1}$ and $g_{2}$ are unknown parameters, $\hat{\mu}=\left(g_{1} g_{2}\right)^{\frac{1}{3}}\left(1-\frac{2}{9 g_{2}}\right)$ and $\hat{\sigma}^{2}=\frac{2 g_{1}^{\frac{2}{3}}}{9 g_{2}^{\frac{1}{3}}}$. Score and orthogonal distances are calculated as below, respectively:

$$
\begin{gathered}
S D_{i}=\sqrt{\sum_{j=1}^{q} \frac{t_{i j}^{2}}{\lambda_{j}}},(i=1,2, \ldots, n) \\
O D_{i}=\left\|x_{i}-\hat{\mu}-P_{p, q} t_{i}^{\prime}\right\|,(i=1,2, \ldots, n)
\end{gathered}
$$

where $t_{i j}$ is a member in $i_{\text {th }}$ row and $j_{\text {th }}$ column of $T_{n, q}$ matrix, which is defined in (1). $t_{i}$ is also $i_{\text {th }}$ row vector of $\mathrm{T}_{\mathrm{n}, \mathrm{q}}$ matrix [22].

In this study, "rrcov" package in the R programming language has been used for calculations regarding the ROBPCA algorithm [23].

\subsection{The technique for Order Preferences by Similarity to an Ideal Solution (TOPSIS)}

Hwang and Yoon [24] suggested the TOPSIS method. In the TOPSIS method, the aim is to select the best solution between different alternatives. The main idea of the TOPSIS method is based on the selection of a solution, which is the nearest to the positive ideal solution and is the farthest to the negative ideal solution. Thus, the TOPSIS method obtains the best sorting [21].

In the TOPSIS method, one needs a decision matrix and a weights vector. Criteria are in rows of the decision matrix, and alternative values are in columns of the decision matrix. Weight vector consists of weights of alternative solutions.

In this study, "topsis" package in the R programming language has been used for calculations regarding the TOPSIS algorithm [25].

\section{Construction of Robust Environmental Performance Index}

This study uses the data set consisted of the values of 180 countries' 24 environmental indicators. These indicators are given in Table 1. We have downloaded the data set from web site EPI 2018 [26].

Table 1. The environmental indicators used in this study

\begin{tabular}{lclc}
\hline Indicator & Code & Indicator & Code \\
\hline Household Solid Fuels & HAD & Marine Protected Areas & MPA \\
$\mathrm{PM}_{2.5}$ Exposure & PME & Biome Protection (National) & TBN \\
$\mathrm{PM}_{2.5}$ Exceedance & PMW & Biome Protection (Global) & TBG \\
Drinking-Water & UWD & Species Protection Index & SPI \\
Sanitation & USD & Representativeness Index & PAR \\
Lead Exposure & PBD & Species Habitat Index & SHI \\
Tree Cover Loss & TCL & Methane Emissions & DMT \\
Fish Stock Status & FSS & $\mathrm{N}_{2} \mathrm{O}$ Emissions & DNT \\
Regional Marine Trophic Index & MTR & Black Carbon Emissions $_{2}$ & DBT \\
$\mathrm{CO}_{2}$ Emissions - Total & DCT & $\mathrm{SO}_{2}$ Emissions & DST \\
$\mathrm{CO}_{2}$ Emissions - Power & DPT & $\mathrm{NO}_{\mathrm{x}}$ Emissions & DXT \\
Sustainable Nitrogen Management & SNM & Wastewater Treatment & WWT \\
\hline
\end{tabular}


Firstly, we investigate whether the data set has outliers by using both classical Mahalanobis distances and the ROBPCA algorithm. While we cannot determine outliers in the classical approach, we determine outliers in the data set via the ROBPCA algorithm. Because classical Mahalanobis distances are based on classical mean vector and sample covariance matrix, which are sensitive to outliers, they may fail to determine outliers. In the robust literature, this case is called masking. The results of outlier detection are given in Table $\mathrm{A}$ in the Appendix.

Moreover, we investigate the relationship between 24 environmental indicators and give the graph of the obtained correlation matrix in Figure A in the Appendix. The $\mathrm{X}$ icon of this graph means that the relationship is statistically unimportant. According to the graphic, we decide to use PCA for dimension reduction because there are many statistically important correlations.

Table 2. The proportion of explained variance

\begin{tabular}{ccccccccccc}
\hline Method & Values & $\boldsymbol{P C}_{\mathbf{1}}$ & $\boldsymbol{P C}_{\mathbf{2}}$ & $\boldsymbol{P C}_{\mathbf{3}}$ & $\boldsymbol{P C}_{\mathbf{4}}$ & $\boldsymbol{P C}_{\mathbf{5}}$ & $\boldsymbol{P C}_{\mathbf{6}}$ & $\boldsymbol{P C}_{\mathbf{7}}$ & $\boldsymbol{P C}_{\mathbf{8}}$ \\
\hline \hline \multirow{2}{*}{ CPCA } & Proportion of Variance & 0.28 & 0.16 & 0.14 & 0.07 & 0.06 & 0.04 & 0.03 & 0.03 \\
& & & & & & & & & &
\end{tabular}

Also, we decide to use robust principal component analysis because the data set has outliers. Table 2 gives the explained variance's proportions obtained from classical PCA (CPCA) and robust PCA (ROBPCA). According to Table 2, 8 components explain $80.8 \%$ of the variance in CPCA, while only 5 components explain $85.1 \%$ of the variance in ROBPCA. Therefore, we use the scores obtained from the ROBPCA, which the number of important components is 5 .

To obtain only a composite index by basing five principal components, we use the TOPSIS method. In the TOPSIS method, we take countries as criteria and the important components as alternative values. We also take the marginal proportions of explained variance as weights for each alternative. Therefore, the first principal component, which explains the biggest proportion of variance, has the biggest weight on the composite index. In this way, the obtained composite index is called the Robust Environmental Performance Index (REPI) because it is not sensitive to outliers. The EPI and the REPI values and the ranks of countries according to these values are given in Table 3. We show these values of indexes on the world map in Figure 1 .

According to Table 3, there are dramatic differences in the results of the REPI and the EPI. The performance rankings of some countries (Armenia, Azerbaijan, Bolivia, Hungary, Czech Republic, Turkmenistan, Makedonia, etc.) decrease, while the performance rankings of other countries (Bahrain, Bangladesh, Chile, China, Malaysia, Maldives, etc.) increase. We detect an essential difference for top countries. Accordingly, the rank of Malta is 1 instead of 4, the rank of Israel is 2 instead of 19, the rank of Sweden is 3 instead of 5, the rank of Finland is 4 instead of 10, the rank of Holland is 5 instead of 18, the rank of South Korea is 6 instead of 60, the rank of Singapore is 7 instead of 49, and the rank of Japan is 8 instea of 20. On the contrary, the rank of Switzerland decreases from 1 to 52, the rank of France decreases from 2 to 10, the rank of Denmark decreases from 3 to 17, the rank of Luxembourg decreases from 7 to 69 and the rank of United Kingdom decreases from 6 to 12. 
Table 3. The Index Values and Ranking of Countries According to EPI2018 and REPI

\begin{tabular}{|c|c|c|c|c|c|c|c|c|c|}
\hline \multirow{2}{*}{ Country } & \multicolumn{2}{|c|}{ EPI 2018} & \multicolumn{2}{|c|}{ REPI } & \multirow{2}{*}{ Country } & \multicolumn{2}{|c|}{ EPI 2018} & \multicolumn{2}{|c|}{ REPI } \\
\hline & Value & Rank & Value & $\operatorname{Ran}$ & & Value & $\operatorname{Ran}$ & Value & Ran \\
\hline Afghanistan & 37.74 & 168 & 31.46 & 161 & Djibouti & 40.04 & 163 & 40.05 & 136 \\
\hline Albania & 65.46 & 40 & 62.83 & 34 & Dominica & 59.38 & 73 & 49.01 & 98 \\
\hline Algeria & 57.18 & 88 & 51.49 & 88 & Dominican Republic & 64.71 & 46 & 60.23 & 46 \\
\hline Angola & 37.44 & 170 & 37.27 & 146 & Ecuador & 57.42 & 87 & 53.47 & 75 \\
\hline Antigua and Barbuda & 59.18 & 76 & 55.08 & 67 & Egypt & 61.21 & 66 & 55.77 & 61 \\
\hline Argentina & 59.3 & 74 & 60.03 & 48 & El Salvador & 53.91 & 106 & 43.58 & 118 \\
\hline Armenia & 62.07 & 63 & 43.07 & 123 & Equatorial Guinea & 60.4 & 71 & 54.62 & 70 \\
\hline Australia & 74.12 & 21 & 67.89 & 19 & Eritrea & 39.34 & 165 & 35.34 & 153 \\
\hline Austria & 78.97 & 8 & 54.89 & 68 & Estonia & 64.31 & 48 & 61.41 & 41 \\
\hline Azerbaijan & 62.33 & 59 & 44.04 & 115 & Ethiopia & 44.78 & 141 & 21.88 & 175 \\
\hline Bahamas & 54.99 & 98 & 52.36 & 81 & Fiji & 53.09 & 107 & 49.77 & 93 \\
\hline Bahrain & 55.15 & 96 & 63.54 & 29 & Finland & 78.64 & 10 & 71.26 & 4 \\
\hline Bangladesh & 29.56 & 179 & 43.44 & 121 & France & 83.95 & 2 & 70.12 & 10 \\
\hline Barbados & 55.76 & 93 & 53.09 & 78 & Gabon & 45.05 & 140 & 42.36 & 126 \\
\hline Belarus & 64.98 & 44 & 48.58 & 101 & The Gambia & 42.42 & 156 & 37.14 & 147 \\
\hline Belgium & 77.38 & 15 & 68.68 & 15 & Georgia & 55.69 & 94 & 53.22 & 77 \\
\hline Belize & 57.79 & 81 & 50.71 & 90 & Germany & 78.37 & 13 & 68.89 & 14 \\
\hline Benin & 38.17 & 167 & 30.50 & 162 & Ghana & 49.66 & 124 & 46.60 & 111 \\
\hline Bhutan & 47.22 & 131 & 30.42 & 164 & Greece & 73.6 & 22 & 64.21 & 26 \\
\hline Bolivia & 55.98 & 92 & 35.66 & 152 & Grenada & 50.93 & 118 & 48.05 & 102 \\
\hline Bosnia and Herzegovina & 41.84 & 158 & 34.23 & 155 & Guatemala & 52.33 & 110 & 51.51 & 86 \\
\hline Botswana & 51.7 & 113 & 32.82 & 156 & Guinea & 46.62 & 134 & 38.58 & 140 \\
\hline Brazil & 60.7 & 69 & 58.08 & 55 & Guinea-Bissau & 44.67 & 143 & 36.48 & 149 \\
\hline Brunei Darussalam & 63.57 & 53 & 61.78 & 39 & Guyana & 47.93 & 128 & 38.52 & 141 \\
\hline Bulgaria & 67.85 & 30 & 59.87 & 49 & Haiti & 33.74 & 174 & 35.17 & 154 \\
\hline Burkina Faso & 42.83 & 154 & 20.97 & 176 & Honduras & 51.51 & 114 & 48.60 & 100 \\
\hline Burundi & 27.43 & 180 & 19.91 & 178 & Hungary & 65.01 & 43 & 46.84 & 110 \\
\hline Cabo Verde & 56.94 & 89 & 47.64 & 107 & Iceland & 78.57 & 11 & 66.54 & 22 \\
\hline Côte d'Ivoire & 45.25 & 139 & 42.52 & 125 & India & 30.57 & 177 & 43.65 & 117 \\
\hline Cambodia & 43.23 & 150 & 43.45 & 120 & Indonesia & 46.92 & 133 & 49.08 & 97 \\
\hline Cameroon & 40.81 & 161 & 31.50 & 160 & Iran & 58.16 & 80 & 52.62 & 80 \\
\hline Canada & 72.18 & 25 & 62.99 & 32 & Iraq & 43.2 & 152 & 36.11 & 150 \\
\hline The central African & 36.42 & 171 & 17.29 & 180 & Ireland & 78.77 & 9 & 69.63 & 11 \\
\hline Chad & 45.34 & 137 & 23.55 & 171 & Israel & 75.01 & 19 & 73.86 & 2 \\
\hline Chile & 57.49 & 84 & 61.92 & 37 & Italy & 76.96 & 16 & 67.06 & 21 \\
\hline China & 50.74 & 120 & 61.79 & 38 & Jamaica & 58.58 & 78 & 48.98 & 99 \\
\hline Colombia & 65.22 & 42 & 63.28 & 30 & Japan & 74.69 & 20 & 70.14 & 8 \\
\hline Comoros & 44.24 & 146 & 38.16 & 143 & Jordan & 62.2 & 62 & 49.54 & 95 \\
\hline Costa Rica & 67.85 & 31 & 57.47 & 57 & Kazakhstan & 54.56 & 101 & 40.65 & 132 \\
\hline Croatia & 65.45 & 41 & 59.02 & 53 & Kenya & 47.25 & 130 & 40.37 & 134 \\
\hline Cuba & 63.42 & 55 & 61.24 & 42 & Kiribati & 55.26 & 95 & 49.37 & 96 \\
\hline Cyprus & 72.6 & 24 & 66.45 & 24 & Kuwait & 62.28 & 61 & 64.25 & 25 \\
\hline Czech Republic & 67.68 & 33 & 47.79 & 104 & Kyrgyzstan & 54.86 & 99 & 32.61 & 157 \\
\hline Dem. Rep. Congo & 30.41 & 178 & 20.35 & 177 & Laos & 42.94 & 153 & 30.20 & 166 \\
\hline Denmark & 81.6 & 3 & 68.32 & 17 & Latvia & 66.12 & 37 & 59.67 & 50 \\
\hline Lebanon & 61.08 & 67 & 60.47 & 44 & São Tomé and Príncipe & 54.01 & 104 & 44.69 & 114 \\
\hline Lesotho & 33.78 & 173 & 29.86 & 167 & Saint Lucia & 56.18 & 91 & 51.80 & 85 \\
\hline Liberia & 41.62 & 160 & 40.06 & 135 & Saint Vincent and the & 66.48 & 36 & 55.33 & 63 \\
\hline Libya & 49.79 & 123 & 46.55 & 112 & Samoa & 54.5 & 102 & 49.74 & 94 \\
\hline Lithuania & 69.33 & 29 & 63.64 & 28 & Saudi Arabia & 57.47 & 86 & 61.44 & 40 \\
\hline Luxembourg & 79.12 & 7 & 54.85 & 69 & Senegal & 49.52 & 126 & 43.21 & 122 \\
\hline Macedonia & 61.06 & 68 & 41.56 & 129 & Serbia & 57.49 & 85 & 41.36 & 130 \\
\hline Madagascar & 33.73 & 175 & 39.23 & 137 & Seychelles & 66.02 & 39 & 52.21 & 83 \\
\hline Malawi & 49.21 & 127 & 22.76 & 172 & Sierra Leone & 42.54 & 155 & 37.50 & 145 \\
\hline Malaysia & 59.22 & 75 & 64.12 & 27 & Singapore & 64.23 & 49 & 70.22 & 7 \\
\hline Maldives & 52.14 & 111 & 55.57 & 62 & Slovakia & 70.6 & 28 & 51.88 & 84 \\
\hline Mali & 43.71 & 147 & 22.22 & 173 & Slovenia & 67.57 & 34 & 47.03 & 109 \\
\hline
\end{tabular}


Table 3. (Continued) The Index Values and Ranking of Countries According to EPI2018 and REPI

\begin{tabular}{|c|c|c|c|c|c|c|c|c|c|}
\hline \multirow{2}{*}{ Country } & \multicolumn{2}{|c|}{ EPI 2018} & \multicolumn{2}{|c|}{ REPI } & \multirow{2}{*}{ Country } & \multicolumn{2}{|c|}{ EPI 2018} & \multicolumn{2}{|c|}{ REPI } \\
\hline & Values & Rank & Values & Rank & & Values & Rank & Values & Rank \\
\hline Malta & 80.9 & 4 & 74.24 & 1 & Solomon Islands & 43.22 & 151 & 41.61 & 128 \\
\hline Mauritania & 39.24 & 166 & 40.77 & 131 & South Africa & 44.73 & 142 & 50.35 & 91 \\
\hline Mauritius & 56.63 & 90 & 52.33 & 82 & South Korea & 62.3 & 60 & 71.05 & 6 \\
\hline Mexico & 59.69 & 72 & 56.71 & 59 & Spain & 78.39 & 12 & 66.52 & 23 \\
\hline Micronesia & 49.8 & 122 & 47.49 & 108 & Sri Lanka & 60.61 & 70 & 52.64 & 79 \\
\hline Moldova & 51.97 & 112 & 42.64 & 124 & Sudan & 51.49 & 115 & 47.77 & 105 \\
\hline Mongolia & 57.51 & 83 & 38.09 & 144 & Suriname & 54.2 & 103 & 50.92 & 89 \\
\hline Montenegro & 61.33 & 65 & 54.14 & 73 & Swaziland & 40.32 & 162 & 30.22 & 165 \\
\hline Morocco & 63.47 & 54 & 55.78 & 60 & Sweden & 80.51 & 5 & 72.45 & 3 \\
\hline Mozambique & 46.37 & 135 & 39.16 & 138 & Switzerland & 87.42 & 1 & 59.11 & 52 \\
\hline Myanmar & 45.32 & 138 & 47.66 & 106 & Taiwan & 72.84 & 23 & 67.81 & 20 \\
\hline Namibia & 58.46 & 79 & 49.94 & 92 & Tajikistan & 47.85 & 129 & 31.70 & 159 \\
\hline Nepal & 31.44 & 176 & 22.16 & 174 & Tanzania & 50.83 & 119 & 43.46 & 119 \\
\hline Netherlands & 75.46 & 18 & 71.23 & 5 & Thailand & 49.88 & 121 & 55.21 & 65 \\
\hline New Zealand & 75.96 & 17 & 67.92 & 18 & Timor-Leste & 49.54 & 125 & 43.84 & 116 \\
\hline Nicaragua & 55.04 & 97 & 51.49 & 87 & Togo & 41.78 & 159 & 31.78 & 158 \\
\hline Niger & 35.74 & 172 & 19.09 & 179 & Tonga & 62.49 & 57 & 54.59 & 71 \\
\hline Nigeria & 54.76 & 100 & 45.45 & 113 & Trinidad and Tobago & 67.36 & 35 & 59.53 & 51 \\
\hline Norway & 77.49 & 14 & 68.60 & 16 & Tunisia & 62.35 & 58 & 61.23 & 43 \\
\hline Oman & 51.32 & 116 & 54.41 & 72 & Turkey & 52.96 & 108 & 53.94 & 74 \\
\hline Pakistan & 37.5 & 169 & 38.94 & 139 & Turkmenistan & 66.1 & 38 & 48.00 & 103 \\
\hline Panama & 62.71 & 56 & 58.57 & 54 & Uganda & 44.28 & 145 & 24.77 & 170 \\
\hline Papua New Guinea & 39.35 & 164 & 36.94 & 148 & Ukraine & 52.87 & 109 & 56.99 & 58 \\
\hline Paraguay & 53.93 & 105 & 36.04 & 151 & United Arab Emirates & 58.9 & 77 & 63.07 & 31 \\
\hline Peru & 61.92 & 64 & 60.35 & 45 & United Kingdom & 79.89 & 6 & 69.37 & 12 \\
\hline Philippines & 57.65 & 82 & 55.32 & 64 & United States of America & 71.19 & 27 & 68.92 & 13 \\
\hline Poland & 64.11 & 50 & 60.10 & 47 & Uruguay & 64.65 & 47 & 62.15 & 36 \\
\hline Portugal & 71.91 & 26 & 62.86 & 33 & Uzbekistan & 45.88 & 136 & 38.42 & 142 \\
\hline Qatar & 67.8 & 32 & 70.13 & 9 & Vanuatu & 44.55 & 144 & 41.69 & 127 \\
\hline Republic of Congo & 42.39 & 157 & 40.45 & 133 & Venezuela & 63.89 & 51 & 55.21 & 66 \\
\hline Romania & 64.78 & 45 & 57.82 & 56 & Viet Nam & 46.96 & 132 & 53.24 & 76 \\
\hline Russia & 63.79 & 52 & 62.32 & 35 & Zambia & 50.97 & 117 & 30.48 & 163 \\
\hline Rwanda & 43.68 & 148 & 25.42 & 168 & Zimbabwe & 43.41 & 149 & 25.04 & 169 \\
\hline
\end{tabular}

(a)

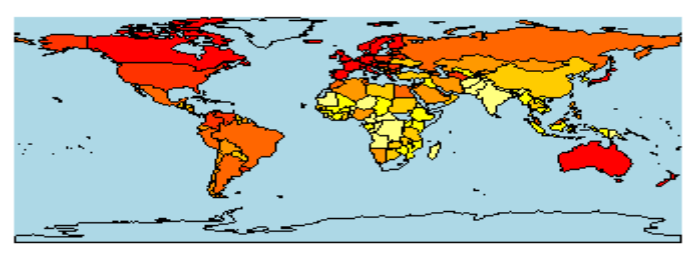

(b)

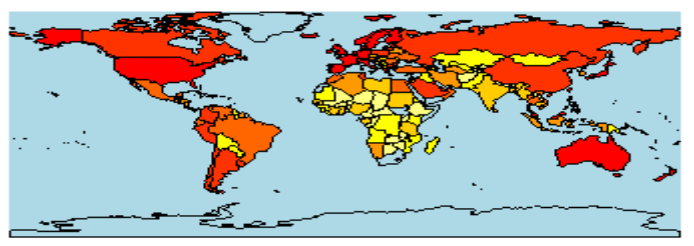

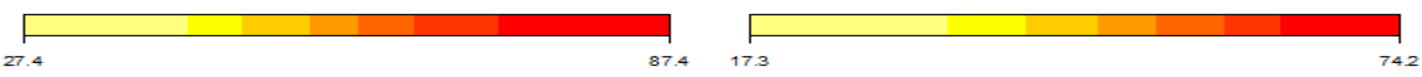

Fig. 1. The world maps according to environmental performance indexes (a) EPI2018 (b) REPI 
These results based on the REPI are more confidential than those based on the EPI because the REPI is not sensitive to outliers in the data set. Moreover, it is seen that African countries have poorer environmental performances than American and European countries, according to both the EPI and the REPI, when maps given in Figure 1 are investigated.

\section{Conclusion}

This study aims to construct a robust composite index, an alternative to the EPI. For this aim, firstly, we have investigated whether the data set has outliers or not and decided the data set has outliers. Therefore, we used the ROBPCA algorithm, a robust principal component analysis, for dimension reduction and obtained five important principal components scores for each country. We have used the TOPSIS method to construct a composite index from five principal components scores. Finally, we have obtained the REPI values, which are not sensitive to outliers in the data set, for each country and have ranked countries according to these index values. When they are compared with the EPI results, the REPI results have dramatic differences. The reason for these differences is the impact of outliers in data sets. Therefore, we suggest using methods that are not sensitive to outliers when constructing a composite index.

\section{Author Contributions}

The author read and approved the last version of the manuscript.

\section{Conflict of Interest}

The author declares no conflict of interest.

\section{References}

[1] E. P. Index, Environmental Performance Index, Yale University and Columbia University: NewHaven, CT, USA.

[2] P. A. Stanwick, S. D. Stanwick, The Relationship between Corporate Social Performance, and Organizational Size, Financial Performance, and Environmental Performance: An Empirical Examination, Journal of Business Ethics 17(2) (1998) 195-204.

[3] D. M. Patten, The Relation between Environmental Performance and Environmental Disclosure: A Research Note, Accounting, Organizations and Society 27(8) (2002) 763-773.

[4] S. A. Al-Tuwaijri, T. E. Christensen, K. E. Hughes, The Relations among Environmental Disclosure, Environmental Performance, and Economic Performance: A Simultaneous Equations Approach, Accounting, Organizations and Society 29(5-6) (2004) 447-471.

[5] P. M. Clarkson, Y. Li, G. D. Richardson, F. P. Vasvari, Revisiting the Relation between Environmental Performance and Environmental Disclosure: An Empirical Analysis, Accounting, Organizations and Society 33(4-5) (2008) 303-327.

[6] J. Wen, Y. Hao, G.-F. Feng, C.-P. Chang, Does Government Ideology Influence Environmentalperformance? Evidence Based on a New Dataset, Economic Systems 40(2) (2016) 232 246.

[7] G. Halkos, A. Zisiadou, Relating Environmental Performance with Socioeconomic and Culturalfactors, Environmental Economics and Policy Studies 20(1) (2018) 69-88.

[8] R. Färe, S. Grosskopf, F. Hernandez-Sancho, Environmental Performance: An Index Number Approach, Resource and Energy Economics 26(4) (2004) 343-352. 
[9] P. Zhou, B. Ang, K. Poh, Slacks-based Efficiency Measures for Modeling Environmental Performance, Ecological Economics 60(1) (2006) 111-118.

[10] P. Zhou, K. L. Poh, B. W. Ang, A Non-Radial DEA Approach to Measuring Environmental Performance, European Journal of Operational Research 178(1) (2007) 1-9.

[11] M. Kortelainen, Dynamic Environmental Performance Analysis: A Malmquist Index Approach, Ecological Economics 64(4) (2008) 701-715.

[12] P. Zhou, B. W. Ang, K. L. Poh, Measuring Environmental Performance under Different Environmental DEA Technologies, Energy Economics 30(1) (2008) 1-14.

[13] W. Liu, J. Tian, L. Chen, W. Lu, Y. Gao, Environmental Performance Analysis of Eco-Industrial Parks in China: A Data Envelopment Analysis Approach, Journal of Industrial Ecology 19(6) (2015) 10701081.

[14] J. R. C.-E. Commission, et al., Handbook on Constructing Composite Indicators: Methodology and User Quide, OECD Publishing, 2008.

[15] R. Ram, Composite Indices of Physical Quality of Life, Basic Needs Fulfilment, and Income: A 'Principal Component' Representation, Journal of Development Economics 11(2) (1982) 227-247.

[16] D. J. Slottje, Measuring the Quality of Life Across Countries, The Review of Economics and Statistics (1991) 684-693.

[17] B. Biswas, F. Caliendo, A Multivariate Analysis of the Human Development Index, Economics Research Institute Study Paper 11 (2002) 1.

[18] D. Lai, Principal Component Analysis on Human Development Indicators of China, Social Indicatorsresearch 61(3) (2003) 319-330.

[19] K. M. Wong, Well-being and Economic Development: A Principal Components Analysis, International Journal of Happiness and Development 1(2) (2013) 131-141.

[20] H. Bulut, Y. Öner, The Evaluation of Socioeconomic Development of Development Agency Regions in Turkey using Classical and Robust Principal Component Analyses, Journal of Applied Statistics 44(16) (2017) 2936-2948.

[21] S. Alpaykut, A Study for Analysing Well-Being for Provinces in Turkey by Using Principal Component Analysis and TOPSIS, Journal of Suleyman Demirel University Institute of Social Sciences 29(4) (2017) 367-395.

[22] M. Hubert, P. J. Rousseeuw, K. Vanden Branden, ROBPCA: A New Approach to robust principal component analysis, Technometrics 47(1) (2005) 64-79.

[23] V. Todorov, P. Filzmoser, An Object-Oriented Framework for Robust Multivariate Analysis, Journal of Statistical Software 32(1) (2009) 1-47.

[24] C.-L. Hwang, K. Yoon, Methods for Multiple Attribute Decision Making, in: Multiple Attribute Decision Making, Springer (1981) 58-191.

[25] B. A. C. Martin, MCDM: Multi-Criteria Decision Making Methods for Crisp Data, $\mathrm{r}$ package version 1.2 (2016) .URL https://CRAN.R-project.org/package=MCDM

[26] Y. University, Environmental Performance Index (2018) .URL:https://epi.yale.edu 


\section{Appendix}

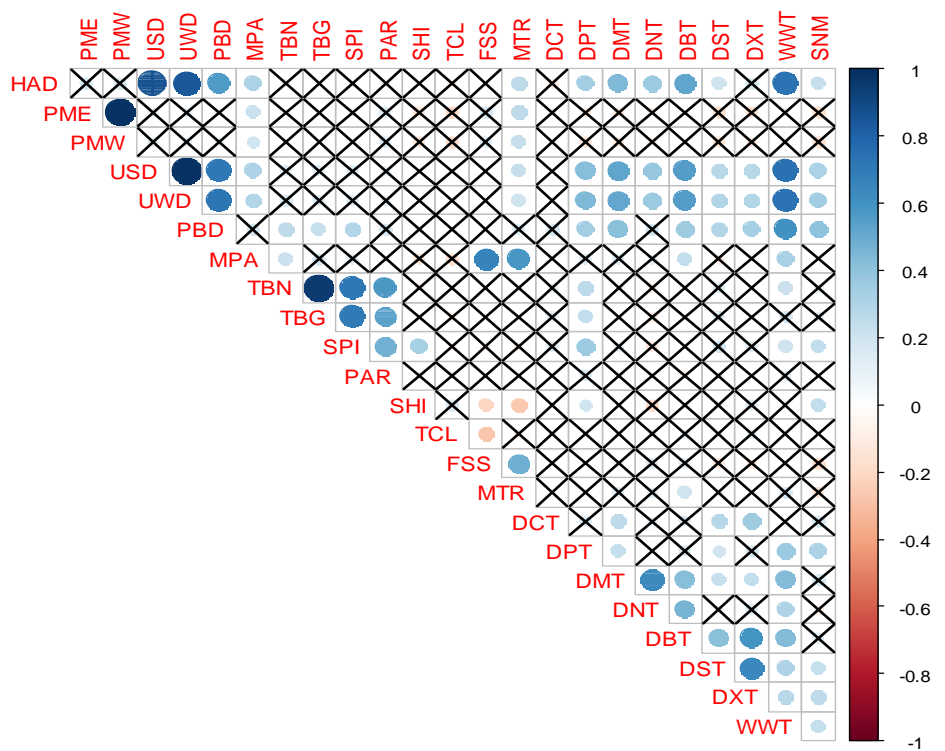

Fig. A. Correlation matrix for environmental indicators

Table A. Outlier Detection

\begin{tabular}{|c|c|c|c|c|c|c|c|c|c|}
\hline Country & $\operatorname{Mah}_{C}$ & SD & OD & Decision & Country & $\operatorname{Mah}_{C}$ & SD & OD & Decision \\
\hline Afghanistan & 37.14 & 4.84 & 82.58 & FALSE & Djibouti & 14.00 & 2.54 & 45.46 & TRUE \\
\hline Albania & 31.39 & 2.56 & 76.74 & TRUE & Dominica & 23.77 & 2.55 & 111.72 & FALSE \\
\hline Algeria & 28.21 & 3.10 & 67.56 & TRUE & Dominican Republic & 15.97 & 2.19 & 46.18 & TRUE \\
\hline Angola & 16.41 & 3.00 & 46.30 & TRUE & Ecuador & 21.97 & 2.58 & 50.36 & TRUE \\
\hline Antigua and Barbuda & 34.28 & 3.03 & 116.98 & FALSE & Egypt & 42.66 & 3.35 & 66.42 & TRUE \\
\hline Argentina & 29.78 & 2.30 & 64.39 & TRUE & El Salvador & 21.67 & 2.88 & 61.76 & TRUE \\
\hline Armenia & 29.15 & 2.63 & 71.40 & TRUE & Equatorial Guinea & 21.17 & 3.89 & 29.69 & TRUE \\
\hline Australia & 18.79 & 3.26 & 37.74 & TRUE & Eritrea & 32.78 & 4.70 & 52.54 & FALSE \\
\hline Austria & 21.72 & 2.96 & 47.66 & TRUE & Estonia & 13.61 & 2.42 & 40.73 & TRUE \\
\hline Azerbaijan & 38.94 & 3.88 & 63.17 & TRUE & Ethiopia & 22.20 & 4.49 & 37.21 & TRUE \\
\hline Bahamas & 23.19 & 3.84 & 45.33 & TRUE & Fiji & 19.64 & 2.14 & 58.48 & TRUE \\
\hline Bahrain & 31.74 & 4.37 & 64.33 & TRUE & Finland & 17.35 & 2.46 & 50.94 & TRUE \\
\hline Bangladesh & 67.70 & 5.74 & 79.49 & FALSE & France & 17.38 & 2.71 & 39.51 & TRUE \\
\hline Barbados & 30.74 & 3.52 & 93.33 & FALSE & Gabon & 31.01 & 3.27 & 52.13 & TRUE \\
\hline Belarus & 13.16 & 2.18 & 32.26 & TRUE & Gambia & 15.03 & 2.38 & 40.92 & TRUE \\
\hline Belgium & 19.76 & 1.86 & 48.80 & TRUE & Georgia & 34.73 & 4.27 & 60.79 & TRUE \\
\hline Belize & 16.34 & 2.55 & 57.53 & TRUE & Germany & 16.39 & 2.48 & 45.88 & TRUE \\
\hline Benin & 16.56 & 2.63 & 51.72 & TRUE & Ghana & 9.53 & 1.82 & 37.38 & TRUE \\
\hline Bhutan & 22.49 & 4.07 & 44.86 & TRUE & Greece & 23.74 & 3.08 & 44.66 & TRUE \\
\hline Bolivia & 16.00 & 2.46 & 35.63 & TRUE & Grenada & 29.50 & 2.51 & 113.88 & FALSE \\
\hline Bosnia and Herzegovina & 31.18 & 3.24 & 84.71 & FALSE & Guatemala & 28.83 & 2.96 & 58.94 & TRUE \\
\hline Botswana & 20.72 & 3.43 & 38.51 & TRUE & Guinea & 18.98 & 3.12 & 39.70 & TRUE \\
\hline Brazil & 31.14 & 2.82 & 49.21 & TRUE & Guinea-Bissau & 15.60 & 2.91 & 34.90 & TRUE \\
\hline Brunei Darussalam & 49.77 & 3.27 & 109.83 & FALSE & Guyana & 26.52 & 2.39 & 88.64 & FALSE \\
\hline Bulgaria & 22.03 & 2.10 & 49.47 & TRUE & Haiti & 27.84 & 3.24 & 52.89 & TRUE \\
\hline Burkina Faso & 13.05 & 2.86 & 28.12 & TRUE & Honduras & 17.65 & 2.50 & 41.55 & TRUE \\
\hline Burundi & 12.82 & 2.86 & 31.44 & TRUE & Hungary & 19.46 & 2.82 & 37.60 & TRUE \\
\hline Cabo Verde & 18.89 & 3.70 & 35.28 & TRUE & Iceland & 33.92 & 2.75 & 81.39 & FALSE \\
\hline Côte d'Ivoire & 17.71 & 2.20 & 56.14 & TRUE & India & 28.61 & 5.67 & 30.80 & FALSE \\
\hline Cambodia & 21.54 & 2.89 & 41.71 & TRUE & Indonesia & 8.35 & 2.38 & 22.62 & TRUE \\
\hline Cameroon & 25.38 & 4.04 & 39.14 & TRUE & Iran & 36.01 & 4.35 & 62.79 & TRUE \\
\hline Canada & 14.87 & 3.27 & 32.86 & TRUE & Iraq & 31.83 & 3.09 & 46.05 & TRUE \\
\hline Central African Republic & 16.02 & 3.16 & 26.76 & TRUE & Ireland & 21.01 & 2.83 & 45.92 & TRUE \\
\hline Chad & 28.70 & 3.34 & 57.87 & TRUE & Israel & 30.45 & 2.75 & 55.63 & TRUE \\
\hline Chile & 32.27 & 5.22 & 43.99 & FALSE & Italy & 14.75 & 2.31 & 36.99 & TRUE \\
\hline China & 12.21 & 2.84 & 28.80 & TRUE & Jamaica & 21.99 & 1.85 & 56.78 & TRUE \\
\hline Colombia & 10.73 & 1.53 & 36.14 & TRUE & Japan & 23.19 & 3.54 & 36.47 & TRUE \\
\hline Comoros & 25.72 & 2.78 & 49.65 & TRUE & Jordan & 31.61 & 3.23 & 65.28 & TRUE \\
\hline Costa Rica & 14.34 & 2.38 & 43.09 & TRUE & Kazakhstan & 33.83 & 2.96 & 65.89 & TRUE \\
\hline Croatia & 20.06 & 2.64 & 45.38 & TRUE & Kenya & 17.69 & 2.26 & 40.71 & TRUE \\
\hline Cuba & 15.07 & 2.41 & 51.40 & TRUE & Kiribati & 29.31 & 3.11 & 103.39 & FALSE \\
\hline Cyprus & 27.11 & 2.86 & 57.96 & TRUE & Kuwait & 34.25 & 2.94 & 89.96 & FALSE \\
\hline Czech Republic & 19.39 & 2.85 & 37.06 & TRUE & Kyrgyzstan & 30.46 & 3.88 & 61.15 & TRUE \\
\hline Dem. Rep. Congo & 28.54 & 5.11 & 51.21 & FALSE & Laos & 28.66 & 5.02 & 29.13 & FALSE \\
\hline Denmark & 16.64 & 2.21 & 46.20 & TRUE & Latvia & 14.64 & 2.67 & 40.76 & TRUE \\
\hline Critical Values & 39.36 & 4.53 & 77.28 & & & 39.36 & 4.53 & 77.28 & \\
\hline
\end{tabular}


Table A. Outlier Detection (Continue)

\begin{tabular}{|c|c|c|c|c|c|c|c|c|c|}
\hline Country & $\operatorname{Mah}_{C}$ & SD & OD & Decision & Country & $\operatorname{Mah}_{C}$ & SD & OD & Decision \\
\hline Lebanon & 26.37 & 3.72 & 46.77 & TRUE & São Tomé and Príncipe & 28.93 & 2.12 & 117.10 & FALSE \\
\hline Lesotho & 17.64 & 2.98 & 38.86 & TRUE & Saint Lucia & 43.98 & 3.52 & 135.91 & FALSE \\
\hline Liberia & 22.94 & 2.67 & 55.91 & TRUE & Saint Vincent and the Grenadines & 18.44 & 2.71 & 40.96 & TRUE \\
\hline Libya & 31.52 & 4.99 & 41.92 & FALSE & Samoa & 25.84 & 2.92 & 94.54 & FALSE \\
\hline Lithuania & 15.54 & 1.43 & 49.76 & TRUE & Saudi Arabia & 15.70 & 2.83 & 49.83 & TRUE \\
\hline Luxembourg & 26.27 & 3.52 & 46.70 & TRUE & Senegal & 8.55 & 2.34 & 26.51 & TRUE \\
\hline Macedonia & 18.12 & 2.10 & 46.99 & TRUE & Serbia & 15.64 & 2.11 & 46.85 & TRUE \\
\hline Madagascar & 33.00 & 3.16 & 60.31 & TRUE & Seychelles & 41.32 & 3.70 & 101.34 & FALSE \\
\hline Malawi & 13.56 & 2.65 & 36.08 & TRUE & Sierra Leone & 22.62 & 2.60 & 39.06 & TRUE \\
\hline Malaysia & 28.60 & 3.35 & 59.82 & TRUE & Singapore & 48.81 & 5.70 & 79.33 & FALSE \\
\hline Maldives & 21.10 & 3.59 & 35.72 & TRUE & Slovakia & 22.53 & 2.91 & 43.10 & TRUE \\
\hline Mali & 20.18 & 3.05 & 34.34 & TRUE & Slovenia & 15.98 & 2.45 & 32.93 & TRUE \\
\hline Malta & 32.86 & 3.80 & 92.14 & FALSE & Solomon Islands & 15.89 & 2.78 & 38.75 & TRUE \\
\hline Mauritania & 23.90 & 3.17 & 51.35 & TRUE & South Africa & 18.17 & 3.41 & 43.32 & TRUE \\
\hline Mauritius & 20.15 & 1.88 & 47.33 & TRUE & South Korea & 32.02 & 3.99 & 61.69 & TRUE \\
\hline Mexico & 11.16 & 1.63 & 48.37 & TRUE & Spain & 15.45 & 2.17 & 41.29 & TRUE \\
\hline Micronesia & 43.49 & 4.89 & 105.69 & FALSE & Sri Lanka & 17.57 & 2.94 & 48.24 & TRUE \\
\hline Moldova & 9.65 & 2.61 & 23.11 & TRUE & Sudan & 36.42 & 6.47 & 41.20 & FALSE \\
\hline Mongolia & 26.61 & 2.46 & 48.52 & TRUE & Suriname & 29.89 & 2.90 & 88.79 & FALSE \\
\hline Montenegro & 31.79 & 2.01 & 61.92 & TRUE & Swaziland & 19.40 & 2.68 & 53.63 & TRUE \\
\hline Morocco & 17.21 & 2.48 & 42.77 & TRUE & Sweden & 17.03 & 2.58 & 48.08 & TRUE \\
\hline Mozambique & 16.42 & 2.87 & 36.38 & TRUE & Switzerland & 27.22 & 4.03 & 34.05 & TRUE \\
\hline Myanmar & 29.86 & 4.57 & 31.48 & FALSE & Taiwan & 21.27 & 3.21 & 40.95 & TRUE \\
\hline Namibia & 27.95 & 3.47 & 57.82 & TRUE & Tajikistan & 29.09 & 5.36 & 37.50 & FALSE \\
\hline Nepal & 47.19 & 5.75 & 46.73 & FALSE & Tanzania & 17.30 & 2.71 & 33.99 & TRUE \\
\hline Netherlands & 17.13 & 2.65 & 47.59 & TRUE & Thailand & 37.07 & 3.49 & 40.67 & TRUE \\
\hline New Zealand & 11.06 & 2.10 & 38.00 & TRUE & Timor-Leste & 13.35 & 2.68 & 37.02 & TRUE \\
\hline Nicaragua & 24.34 & 3.84 & 40.99 & TRUE & Togo & 30.06 & 4.08 & 72.13 & TRUE \\
\hline Niger & 18.44 & 3.23 & 47.25 & TRUE & Tonga & 35.89 & 3.99 & 105.62 & FALSE \\
\hline Nigeria & 17.93 & 3.31 & 28.50 & TRUE & Trinidad and Tobago & 28.69 & 2.80 & 59.20 & TRUE \\
\hline Norway & 18.24 & 3.18 & 41.76 & TRUE & Tunisia & 20.85 & 2.62 & 46.97 & TRUE \\
\hline Oman & 29.00 & 3.98 & 58.47 & TRUE & Turkey & 16.85 & 3.14 & 45.37 & TRUE \\
\hline Pakistan & 31.09 & 6.07 & 37.91 & FALSE & Turkmenistan & 33.01 & 3.22 & 60.17 & TRUE \\
\hline Panama & 13.20 & 2.78 & 27.65 & TRUE & Uganda & 10.67 & 2.67 & 17.03 & TRUE \\
\hline Papua New Guinea & 20.58 & 2.76 & 55.59 & TRUE & Ukraine & 20.87 & 2.81 & 47.67 & TRUE \\
\hline Paraguay & 31.18 & 4.66 & 43.90 & FALSE & United Arab Emirates & 41.79 & 2.24 & 100.27 & FALSE \\
\hline Peru & 15.63 & 2.66 & 30.39 & TRUE & United Kingdom & 18.76 & 3.07 & 45.88 & TRUE \\
\hline Philippines & 19.86 & 1.95 & 44.49 & TRUE & United States of America & 31.40 & 2.39 & 40.21 & TRUE \\
\hline Poland & 22.87 & 2.54 & 57.67 & TRUE & Uruguay & 38.47 & 3.59 & 87.97 & FALSE \\
\hline Portugal & 30.64 & 2.13 & 60.00 & TRUE & Uzbekistan & 29.48 & 4.94 & 48.61 & FALSE \\
\hline Qatar & 20.21 & 3.10 & 51.45 & TRUE & Vanuatu & 18.73 & 2.99 & 57.38 & TRUE \\
\hline Republic of Congo & 26.25 & 3.89 & 45.24 & TRUE & Venezuela & 23.42 & 3.75 & 49.59 & TRUE \\
\hline Romania & 12.15 & 1.82 & 43.08 & TRUE & Viet Nam & 18.87 & 3.33 & 40.50 & TRUE \\
\hline Russia & 13.55 & 2.17 & 30.24 & TRUE & Zambia & 17.62 & 2.76 & 50.04 & TRUE \\
\hline \multirow[t]{2}{*}{ Rwanda } & 19.20 & 2.59 & 39.96 & TRUE & Zimbabwe & 20.56 & 3.46 & 38.00 & TRUE \\
\hline & 39.36 & 4.53 & 77.28 & & & 39.36 & 4.53 & 77.28 & \\
\hline
\end{tabular}

